Article

\title{
Enhanced Desilication of High Alumina Fly Ash by Combining Physical and Chemical Activation
}

\author{
Yanbing Gong ${ }^{1,2}$, Junmin Sun ${ }^{2}$, Shu-Ying Sun ${ }^{3}$, Guozhi Lu ${ }^{1}$ and Ting-An Zhang ${ }^{1, *}$ \\ 1 Key Laboratory of Ecological Metallurgy of Multi-metal Intergrown Ores of Ministry of Education, \\ Special Metallurgy and Process Engineering Institute, Northeastern University, Shenyang 110819, China; \\ gongyb2001@163.com (Y.G.); lvgz@smm.neu.edu.cn (G.L.) \\ 2 High-alumina Coal Resources Development and Utilization R\&D Center, Datang International Power \\ Generation Co., Ltd., Hohhot 010050, China; sunjmdt@163.com \\ 3 National Engineering Research Center for Integrated Utilization of Salt Lake Resource, East China \\ University of Science and Technology, Shanghai 200237, China; shysun@ecust.edu.cn \\ * Correspondence: zta2000@163.net; Tel./Fax: +86-024-8368-1563
}

Received: 14 March 2019; Accepted: 2 April 2019; Published: 4 April 2019

\begin{abstract}
In this work, a physical-chemical activation desilication process was proposed to extract silica from high alumina fly ash (HAFA). The effects of fly ash size, hydrochloric acid concentration, acid activation time, and reaction temperature on the desilication efficiency were investigated comprehensively. The phase and morphology of the original fly ash and desilicated fly ash were analyzed by X-ray diffraction (XRD) and scanning electron microscopy-energy-dispersive X-ray spectroscopy (SEM-EDS). Compared with the traditional desilication process, the physical-chemical activation desilication efficiency is further increased from $38.4 \%$ to $53.2 \%$ under the optimal conditions. Additionally, the kinetic rules and equations were confirmed by the experimental data fitting with shrinking core model of liquid-solid multiphase reaction. Kinetic studies show that the enhanced desilication process is divided into two processes, and both steps of the two-step reaction is controlled by chemical reaction, and the earlier stage activation energy is $52.05 \mathrm{~kJ} / \mathrm{mol}$ and the later stage activation energy is $58.45 \mathrm{~kJ} / \mathrm{mol}$. The results of mechanism analysis show that physical activation breaks the link between the crystalline phase and the amorphous phase, and then a small amount of alkali-soluble alumina in the amorphous phase is removed by acid activation, thereby suppressing the generation of side reactions of the zeolite phase.
\end{abstract}

Keywords: high alumina fly ash; desilication rate; physical-chemical activation; alumina silica mass ratio; kinetics

\section{Introduction}

High alumina fly ash (HAFA) is a byproduct of high-temperature combustion of high-alumina coal in thermal power plants. The annual emission of HAFA is approximately 30 million tons [1]. Except for a small amount that is utilized, most of the HAFA is currently stockpiled in northwestern China, not only occupying farmland, but also giving rise to severe pollution of water, atmosphere, and soil [2,3]. On the other hand, the high alumina content (approximately 50\%) in high alumina fly ash makes it a valuable recycling resource. Furthermore, HAFA contains critical metals such as gallium [4], lithium [5], and rare earths [6,7] that can be extracted in the alumina extraction process as byproducts. Many extraction techniques, such as predesilication soda lime sintering [8], limestone sintering [9], acid leaching [10,11], ammonium sulfate [12] and submolten salt methods [13], have been developed to extract alumina from HAFA. Only the predesilication soda lime sintering process was carried out at an industrial scale (200 kt per year) by China Datang Corporation in the province of 
Inner Mongolia [14]. This formed a circular economy industry (shown in Figure 1) in Tuoketou County, Inner Mongolia. The recycling route of thermal power plant HAFA is presented in Figure 1.

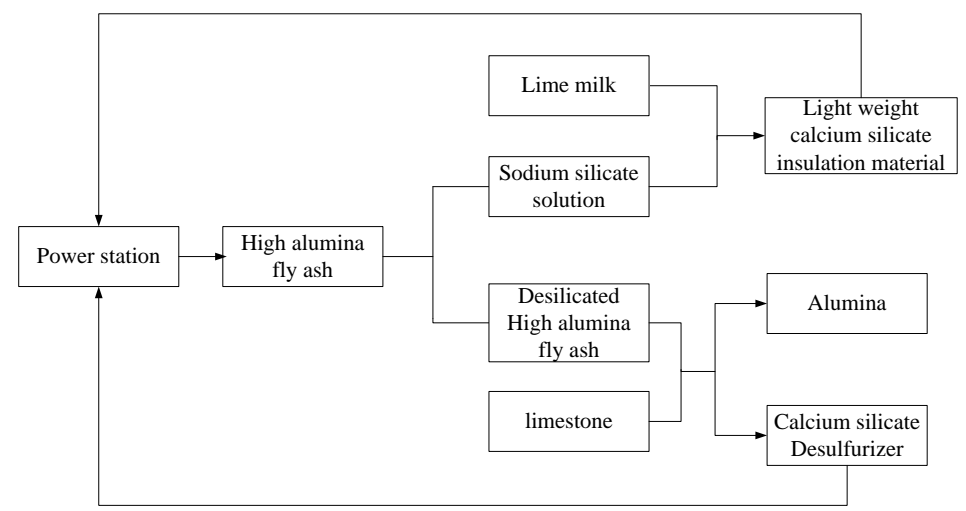

Figure 1. Recycling route of thermal power plant high alumina fly ash (HAFA).

Here, a traditional alkali predesilication method was used to obtain desilicated high alumina fly ash (DHAFA) and sodium silicate solution. The main problem for this technology is that the $\mathrm{Al}_{2} \mathrm{O}_{3} / \mathrm{SiO}_{2}$ mass ratio (A/S) is only elevated to 1.7-1.9. Not only does this make the desilication rate lower, it also increases the difficulty of extraction of alumina by the soda lime sintering process [15]. Because of the low A/S of DHAFA, the main reaction equipment rotary kiln often scabs the inner wall, forming large clinker eggs, and forming hard clinker [16], giving rise to the consequent decrease of the alumina extraction rate, damage to equipment, and increased production cost. Therefore, it is necessary to improve the desilication rate.

$$
2 \mathrm{NaOH}+\mathrm{SiO}_{2} \text { (amorphous) }=\mathrm{Na}_{2} \mathrm{SiO}_{3}+\mathrm{H}_{2} \mathrm{O} \text { (main reaction) }
$$

$10 \mathrm{Na}_{2} \mathrm{SiO}_{3}+3 \mathrm{Al}_{2} \mathrm{O}_{3}$ (amorphous) $+19 \mathrm{H}_{2} \mathrm{O}=\mathrm{Na}_{6} \mathrm{Al}_{6} \mathrm{Si}_{10} \mathrm{O}_{32} \cdot 12 \mathrm{H}_{2} \mathrm{O} \downarrow+14 \mathrm{NaOH}$ (side reaction)

Many researchers have reported that the amorphous $\mathrm{SiO}_{2}$ in the high alumina fly ash can be selectively dissolved in an $\mathrm{NaOH}$ solution [17], thereby leading to a decrease in the amount of silicon-calcium slag generated during the subsequent extraction process of $\mathrm{Al}_{2} \mathrm{O}_{3}$ and achieving the efficient recovery of the silicon resource $[18,19]$. These studies also indicated that the final products were significantly affected by the reaction conditions $[20,21]$. The mechanism of traditional predesilication can be clearly explained as follows: the amorphous $\mathrm{SiO}_{2}$ in the HAFA dissolved in an $\mathrm{NaOH}$ solution and formed sodium silicate as the main reaction (Equation (1)), and meanwhile, a small amount of $\mathrm{Al}_{2} \mathrm{O}_{3}$ was dissolved in an $\mathrm{NaOH}$ solution and formed sodium aluminate, and then sodium silicate reacted with sodium aluminate and formed zeolite as a side reaction (Equation (2)) that inhibits the desilication rate. Zhang et al. [22] has investigated a new process to improve the desilication rate of HAFA. The process is divided into three steps; traditional desilication, acid activation, and secondary desilication. Though the A/S of HAFA is raised from 1.2 to 2.85, the acid activation process consumes a large amount of acid to neutralize the alkali of zeolite generated in reaction Equation (2), so it is uneconomical. A desilication process after 12-h alkali pretreatment [23] was used to improve the A/S of DHAFA from 1.92 to 2.51, and the mechanism can be explained as the zeolite P generation in the pretreatment process blocking the formation of hydroxysodalite in the desilication process. It was found that the desilicated slurry can easily settle at the bottom of the tank and is difficult to filter after a long time of stirring in actual industrial production. A mechanism-chemical synergistic activation desilication process is used to prepare mullite ceramic materials [24]. The process uses harsh reaction conditions to remove the impurities in HAFA. The mechanism [25] has been analyzed. However, the specific effect of the reaction conditions and kinetics of desilication process were not described. 
Based on the previous work [21-23], in this study, a novel process based on physical and chemical activation was developed in order to inhibit the side reaction during desilication and to increase the desilication efficiency. This process is moderate, controllable, and easy to transfer to industrial use. Moreover, the $\mathrm{Al}_{2} \mathrm{O}_{3} / \mathrm{SiO}_{2}$ ratio in desilication fly ash was significantly improved, which is beneficial to the subsequent $\mathrm{Al}_{2} \mathrm{O}_{3}$ extraction process. The effect of the activation reaction conditions on the desilication efficiency and its mechanism were investigated, and the kinetic rules and equations of the $\mathrm{SiO}_{2}$ leaching process were confirmed.

\section{Materials and Methods}

\subsection{Materials}

Hydrochloric acid (Beijing Chemical Works, Beijing, China, 36-38 wt. \%) and $\mathrm{NaOH}$ (Sinopharm Chemical Reagent Co., Ltd., Shanghai, China, $\geq 96 \mathrm{wt}$. \%) used in this study were of the analytical grade. HAFA was generated by a coal-fired boiler of a power plant of the Inner Mongolia Datang International Tuoketuo Power Generation Co., Ltd., Hohhot, China.

Table 1 summarizes the chemical composition of the original fly ash. The metal component contents were evaluated by chemical analysis methods. Table 1 shows that $\mathrm{Al}_{2} \mathrm{O}_{3}$ and $\mathrm{SiO}_{2}$ were the main components of the fly ash. Small amounts of iron oxide and calcium oxide are also present. Thus, this kind of fly ash had a high value for aluminum and silicon production. Additionally, the original fly ash contains a certain amount of rare metals $\mathrm{Ga}$ and $\mathrm{Li}$.

Table 1. Chemical composition of HAFA.

\begin{tabular}{ccccccccc}
\hline Composition & $\mathrm{Al}_{2} \mathrm{O}_{3}$ & $\mathrm{SiO}_{2}$ & $\mathrm{Fe}_{2} \mathrm{O}_{3}$ & $\mathrm{CaO}$ & $\mathrm{Na}_{2} \mathrm{O}$ & $\mathbf{L i}$ & $\mathrm{Ga}$ & $\mathrm{A} / \mathrm{S}$ \\
\hline Content (wt. \%) & 51.38 & 37.97 & 2.01 & 2.00 & 0.38 & 0.0384 & 0.0076 & 1.35 \\
\hline
\end{tabular}

\subsection{Processes and Methods}

The physical-chemical activation desilication process includes three steps: "physical activation", "chemical activation", and "alkali predesilication".

During physical activation, the HAFA was milled for different times $(5,15,30,45$, and $60 \mathrm{~s})$ in a circular disk milling machine with a filling rate of approximately $60 \%$.

During chemical activation, the milling HAFA was activated by hydrochloric acid with different acid concentration $(4 \%, 6 \%, 8 \%$, and $10 \%)$, reaction temperatures $\left(30,60\right.$, and $\left.90{ }^{\circ} \mathrm{C}\right)$, and reaction times $(0.5,1,1.5,2$, and $2.5 \mathrm{~h})$ under a determined $L / S$ ratio (equal to 4$)$. The slurries were then filtered to obtain solid pretreatment HAFA (PHAFA).

During alkali predesilication, the original fly ash or physical-chemical activated solid was mixed with $\mathrm{NaOH}$ solutions with different alkali concentrations $\left(\mathrm{Na}_{2} \mathrm{O}\right.$ concentrations of $100,120,140,160$ $\mathrm{g} / \mathrm{L})$, reaction times $(10,20,30,60,90,120,150$, and $180 \mathrm{~min})$ under the determined conditions $\left(T=95^{\circ} \mathrm{C}, L / S=3.5\right)$ during the alkali predesilication. The slurries were filtered to obtain DHAFA or intensified DHAFA (IDHAFA).

The silica leaching ratio was calculated as follows:

$$
\eta S_{i} O_{2}=\frac{W D-W_{1} D_{1}}{W D} \times 100 \%
$$

where $\eta$ is the desilication rate, $W$ is the mass of HAFA, $W_{1}$ is the mass of DHAFA, $D$ is the percentage content of $\mathrm{SiO}_{2}$ in HAFA, and $D_{1}$ is the percentage content of $\mathrm{SiO}_{2}$ in DHAFA or IDHAFA.

\subsection{Characterization}

The chemical composition of HAFA was analyzed by chemical analysis methods. Particle size distribution of HAFA was evaluated using a Sympatec GmbH particle size analyzer (OASIS/Dry, 
Sympatec $\mathrm{GmbH}$, Clausthal-Zellerfeld, Germany). The surface structure and the distribution of the elements were observed by scanning electron microscopy (JEOL5800SV, JEOL, Tokyo, Japan). The phase composition of HAFA was evaluated by $X$-ray diffraction ( $X^{\prime}$ Pert PRO MPD, PANalytical B.V., Almelo, The Netherlands). The specific surface area and pore size analysis were performed using a Nova4000e high-speed surface tester (Nova4000e, Quantachrome, Boynton Beach, FL, USA). The molybdenum blue colorimetric method can be used to examine the content of $\mathrm{SiO}_{2}$ in the filtrate.

\section{Results and Discussion}

\subsection{Effects of Physical Activation on the Desilication Rate}

Figure 2 shows the effect of physical activation time on the desilication rate, and $\mathrm{A} / \mathrm{S}$ and $\mathrm{Na}_{2} \mathrm{O}$ content of IDHAFA under acid activation conditions $\left(T=90^{\circ} \mathrm{C}\right.$, acid concentration $6 \%, L / S=4$ and $t=1 \mathrm{~h})$ and alkali predesilication conditions $\left(T=95^{\circ} \mathrm{C}, C=120 \mathrm{~g} / \mathrm{L}, L / S=3\right.$, and $\left.t=2.5 \mathrm{~h}\right)$. It is observed that the desilication rate of HAFA is as high as $47 \%$ only due to the chemical activation. However, the desilication rate of HAFA is further improved to $51.9 \%$ after combined physical and chemical activation. Moreover, the alkali content of IDHAFA is decreased, indicating that the side reaction of the desilication process is suppressed, thereby improving the desilication rate. Considering the cost and effect of physical activation data presented in Table 2, the optimal activation time is $15 \mathrm{~s}$.
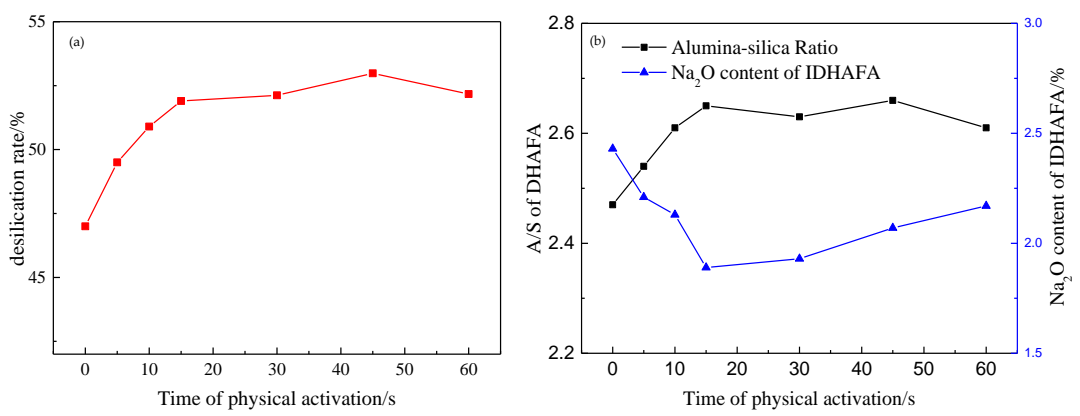

Figure 2. Effect of physical activation time: (a) desilication rate, (b) $\mathrm{A} / \mathrm{S}$ and $\mathrm{Na}_{2} \mathrm{O}$ content of IDHAFA.

Table 2. Effect of physical activation time on the particle size of HAFA $(\mu \mathrm{m})$.

\begin{tabular}{cccccccccc}
\hline Time/s & $\mathbf{0}$ & $\mathbf{5}$ & $\mathbf{1 0}$ & $\mathbf{1 5}$ & $\mathbf{2 0}$ & $\mathbf{2 5}$ & $\mathbf{3 0}$ & $\mathbf{4 5}$ & $\mathbf{6 0}$ \\
\hline $\mathrm{D} 50 / \mu \mathrm{m}$ & 23.03 & 5.22 & 4.86 & 4.36 & 3.37 & 3.12 & 2.84 & 2.02 & 2.01 \\
\hline
\end{tabular}

\subsection{Effects of Chemical Activation on the Desilication Rate}

The data for the effects of acid concentration, reaction temperature, and reaction time on the desilication rate, A/S of DHAFA and $\mathrm{Na}_{2} \mathrm{O}$ content of IDHAFA for physical activation time of $15 \mathrm{~s}$, and alkali predesilication conditions $\left(T=95^{\circ} \mathrm{C}, \mathrm{C}=120 \mathrm{~g} / \mathrm{L}, L / S=3\right.$, and $\left.t=2.5 \mathrm{~h}\right)$ are shown in Figures 3 and 4 .
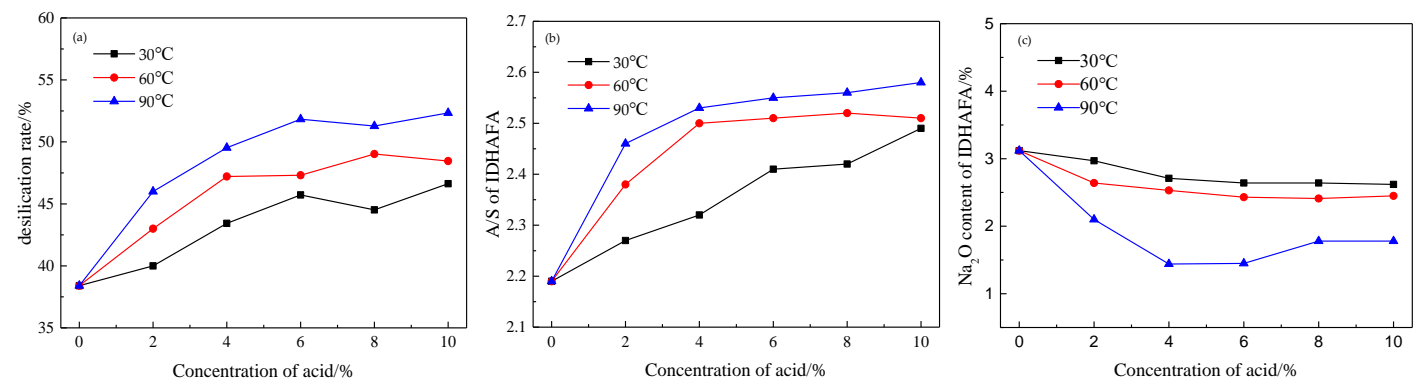

Figure 3. Effect of concentration of acid: (a) desilication rate, (b) A/S of intensified desilicated high alumina fly ash (IDHAFA), (c) $\mathrm{Na}_{2} \mathrm{O}$ content of IDHAFA. 

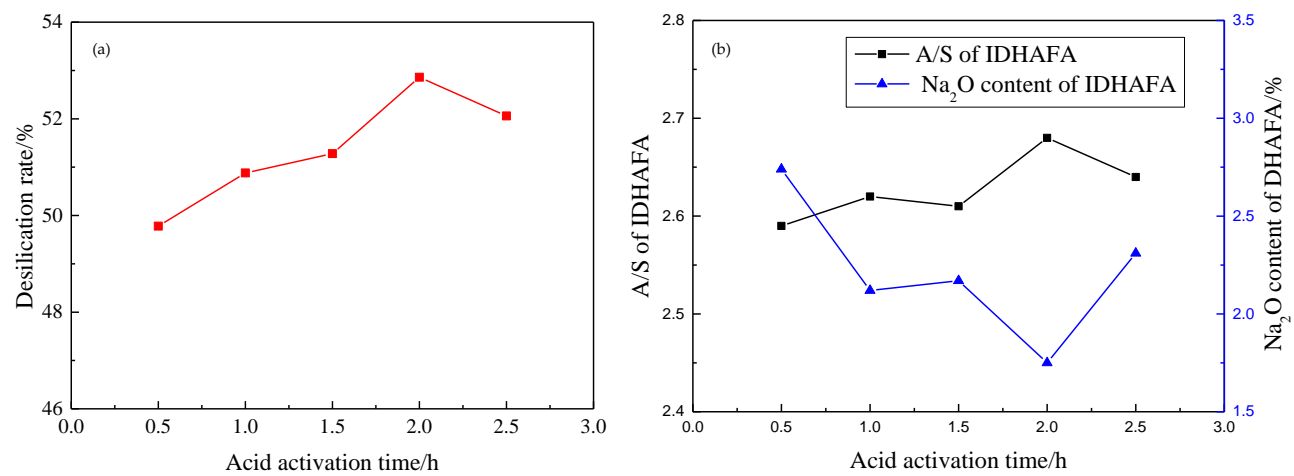

Figure 4. Effect of acid activation time $\left(T=95^{\circ} \mathrm{C}\right)$ : (a) desilication rate, $(\mathbf{b}) \mathrm{A} / \mathrm{S}$ and $\mathrm{Na}_{2} \mathrm{O}$ of IDHAFA.

It is observed from Figure $3 a$ that the desilication rate of the HAFA after acid activation is greatly improved compared with the conventional predesilication. The desilication rate is also improved with increasing temperature. The desilication rate is enhanced by more than $50 \%$ when the temperature is $90{ }^{\circ} \mathrm{C}$. In addition, an increase in the acid concentration also enhances the desilication rate. It is observed from Figure $3 b, c$ that the variation of the IDHAFA aluminum: silicon ratio is completely consistent with the desilication rate, but the change of the sodium oxide content in the IDHAFA shows a completely opposite trend to that of the desilication rate. This shows that the desilication fly ash aluminum: silicon ratio can reflect the desilication rate, while the sodium oxide content indicates the degree of the side reaction, which is inversely proportional to the desilication rate.

Figure $4 \mathrm{a}$ shows that the effect of the acid activation time on the desilication rate is also relatively large. In the range of $0-2 \mathrm{~h}$, the desilication rate increases strongly with increased acid activation time. Flocculent silica gel was produced in the chemical activation process after $2 \mathrm{~h}$, which makes the slurry becomes very viscous and difficult to filter, and the filter cake contains a large amount of acid, resulting in lower efficiency in desilication. It is observed from Figure $4 \mathrm{~b}$ that the change in the desilication rate is consistent with the change in the ratio of IDHAFA to aluminum and silicon, and at the same time with the desilication powder. The change in the content of sodium oxide in IDHAFA is inversely proportional. Based on these experiments, it can be concluded that the optimal conditions for acid activation are: temperature of $90^{\circ} \mathrm{C}$, acid concentration of $6 \%$, liquid: solid ratio of $4: 1$, and acid activation reaction time of $2 \mathrm{~h}$. After chemical activation under these conditions, the metal ions are partially leached into the solution: and the dissolution rates of iron oxide and calcium oxide were $37.4 \%$ and $38.2 \%$, respectively. Meanwhile, $\mathrm{Al}_{2} \mathrm{O}_{3}$ reached a dissolution rate of approximately $3.0 \%$, but $\mathrm{SiO}_{2}$ is hardly dissolved during the hydrochloric acid activation.

\subsection{Effects of Alkali Predesilication on the Desilication Rate}

Figures 5 and 6 show the alkali concentration, reaction time, and temperature effects on the direct desilication of the original fly ash and desilication after activation for the physical activation time of $15 \mathrm{~s}$, and acid activation conditions $\left(T=90^{\circ} \mathrm{C}\right.$, acid concentration $6 \%, L / S=4$ and $\left.t=2 \mathrm{~h}\right)$. 


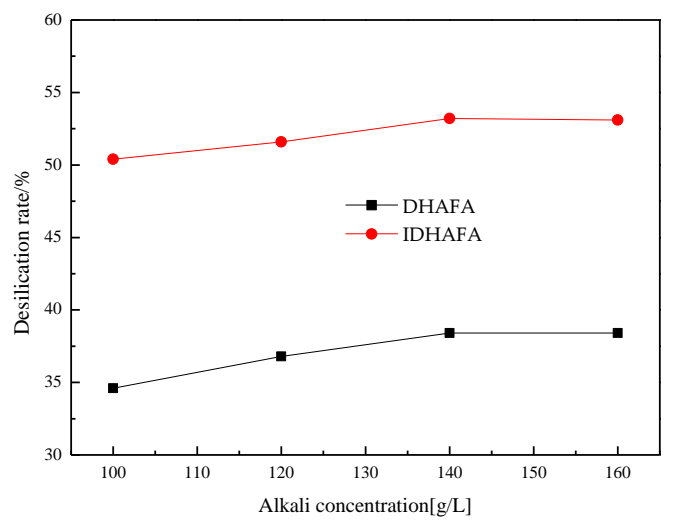

Figure 5. Effect of alkali concentration on the desilication rate of IDHAFA and DHAFA (Predesilication conditions: $T=95^{\circ} \mathrm{C}, L / S=3.5$, and $t=150 \mathrm{~min}$ ).

It can be concluded from Figure 5 that the improvement of desilication efficiency after enhanced desilication is obvious. Generally speaking, increasing the concentration of sodium hydroxide is beneficial to the progress of reaction Equation (1). However, a high concentration of sodium hydroxide will also promote the progress of reaction Equation (2), and this is detrimental to desilication. According to the results in Figure 5, $\mathrm{C}\left(\mathrm{Na}_{2} \mathrm{O}\right)=140 \mathrm{~g} / \mathrm{L}$ was required for the maximal desilication rate.

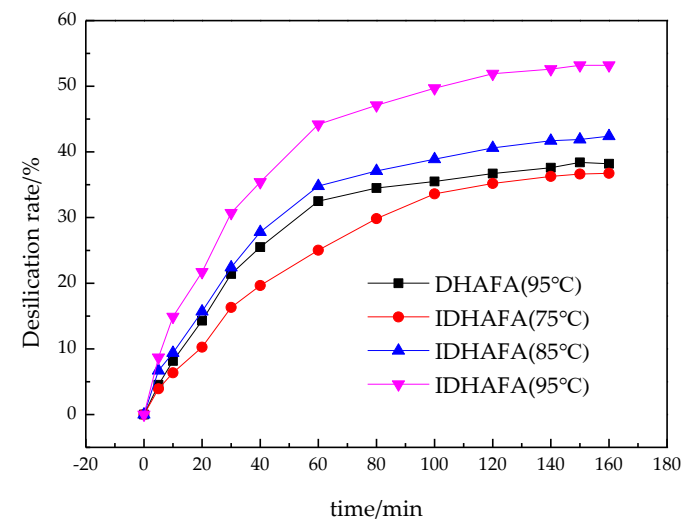

Figure 6. Effect of reaction time and temperature on the desilication rate of IDHAFA and DHAFA (Predesilication conditions: $C\left(\mathrm{Na}_{2} \mathrm{O}\right)=140 \mathrm{~g} / \mathrm{L}$, and $L / S=3.5$ ).

It can be seen from Figure 6 that the effect of temperature on the desilication efficiency is very large. Although the enhanced desilication rate is much higher than the direct desilication at $95^{\circ} \mathrm{C}$, the desilication rate is greatly reduced at $75^{\circ} \mathrm{C}$. In the $0-160 \mathrm{~min}$ period, the desilication rate increases with the increase of reaction time. However, as the reaction time increases, the reaction rate continues to decrease. The change of reaction rate divides the desilication reaction into two stages.

The data shown in Figures 5 and 6 clearly illustrate the great difference between the two desilication methods. Compared with direct desilication, the desilication rate after activation is greatly improved from $38.4 \%$ to $53.2 \%$ under the predesilication conditions $\left(T=95^{\circ} \mathrm{C}, \mathrm{C}\left(\mathrm{Na}_{2} \mathrm{O}\right)=140 \mathrm{~g} / \mathrm{L}\right.$, $L / S=3.5$, and $t=2.5 \mathrm{~h}$ ).

\subsection{Kinetics of the Desilication Process}

As already mentioned, the reaction Equation (1) is the main reaction of the desilication reaction process. In order to examine the $\mathrm{SiO}_{2}$ leaching kinetics of the enhanced desilication process, a shrinking core model of a liquid-solid multiphase reaction was used to fit the $\mathrm{SiO}_{2}$ leaching kinetics data. According to the reaction rate changing node in Figure 6, the $\mathrm{SiO}_{2}$ leaching process is divided into two stages, and the fitting data are shown in Figure 7. 

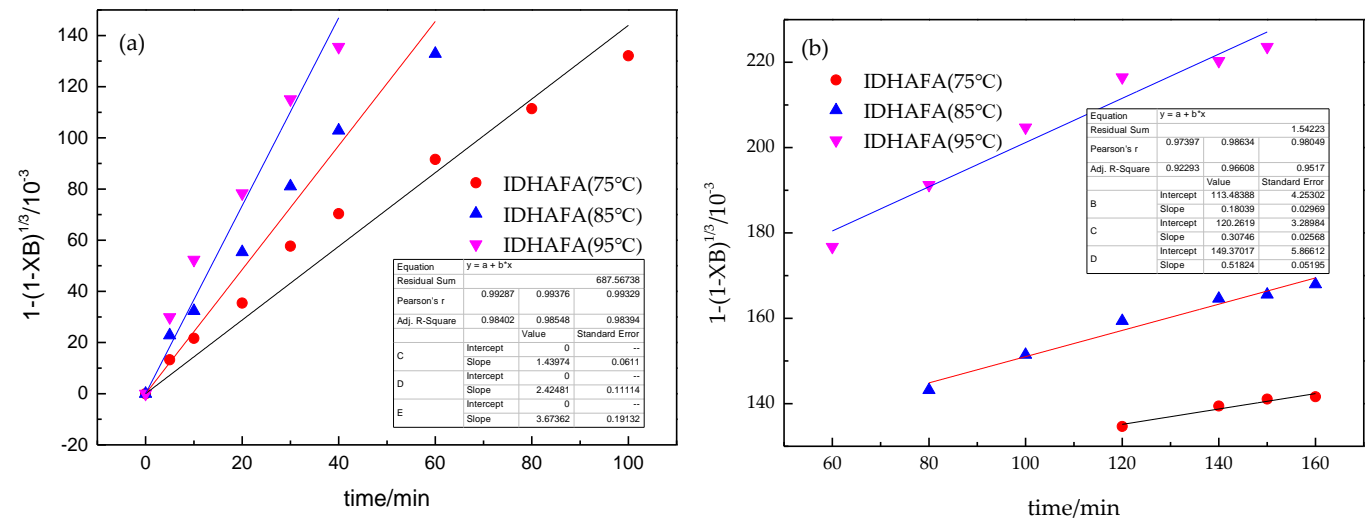

Figure 7. Mathematical fitting of data of $\mathrm{SiO}_{2}$ leaching kinetics in enhanced desilication process: (a) The earlier stage, (b) The later stage.

There are two stages in the traditional desilication reaction process; the earlier stage is limited by the surface reaction, while in the later stage, the internal diffusion on the solid product layer is the rate-controlling step [26]. But, the physical-chemical activation desilication is significantly different. As exhibited in Figure 7a,b, the desilication process was controlled by chemical reaction in 0-160 min, in the temperature range of $75-95^{\circ} \mathrm{C}$, and both stages are controlled by chemical reaction. Under experimental conditions, the kinetic equation can be written as

$$
\begin{aligned}
& 1-\left(1-X_{\mathrm{B}}\right)^{1 / 3}=k_{1} t \\
& 1-\left(1-X_{\mathrm{B}}\right)^{1 / 3}=k_{2} t
\end{aligned}
$$

where $X_{\mathrm{B}}$ is the desilication rate, $t$ is the reaction time, $k_{1}$ is the rate constant of the earlier stage, $k_{2}$ is the rate constant of the later stage.

According to the Arrhenius equation $\ln k=\ln A-E a / R T$, Plot $\ln k$ to $1 / T$, as exhibited in Figure 8 , both of the two stages have a good linear relationship. Calculated based on the slope of the fitted curve, the earlier stage's activation energy is $52.05 \mathrm{~kJ} / \mathrm{mol}$, the later stage's activation energy is $58.45 \mathrm{~kJ} / \mathrm{mol}$.

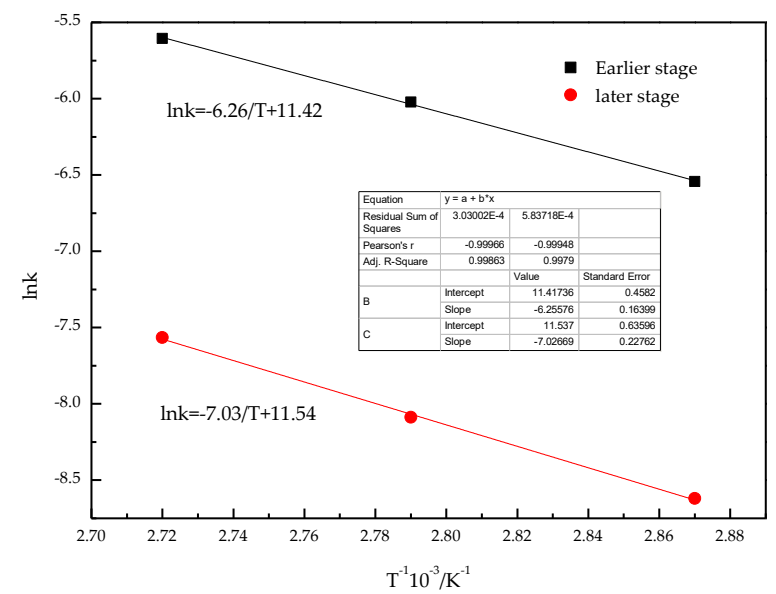

Figure 8. Arrhenius plot of $\mathrm{SiO}_{2}$ leaching kinetics in the enhanced desilication process.

In the traditional desilication process, as the reaction time extends, the formation of zeolite in the side reaction increases, and a film is gradually formed in the fly ash particles. Therefore, the reaction is controlled by chemical reaction in the earlier stage and by diffusion in the later stage. But, the amount of zeolite is greatly reduced by enhanced desilication, so diffusion control is eliminated, and the 
enhanced desilication process is only controlled by the chemical reaction, which indicates that the set-up of the previous kinetic model is correct.

\subsection{Mechanism}

As shown in Figure 9, the phases of PHAFA and HAFA are basically the same, indicating that the physical-chemical activation process does not change the phase composition of HAFA. Moreover, according to the previous experimental results, the treatment only removed part of the iron oxide, calcium oxide, and a small amount of alumina; however, mullite, corundum, quartz, and glass-phase silica did not react, so there is no phase change before and after treatment. The bulge between $15^{\circ}$ and $25^{\circ}$ in the XRD patterns of both DHAFA and IDHAFA disappears because the activated amorphous $\mathrm{SiO}_{2}$ was dissolved by the alkali solution during desilication, and the new zeolite phase appears in DHAFA because the soluble alumina enters the desilication solution and reacts with sodium silicate. It is also observed that there are few zeolite peaks in IDHAFA because the amount of soluble alumina decreases during the activation process, weakening the spontaneous side reaction (zeolite).

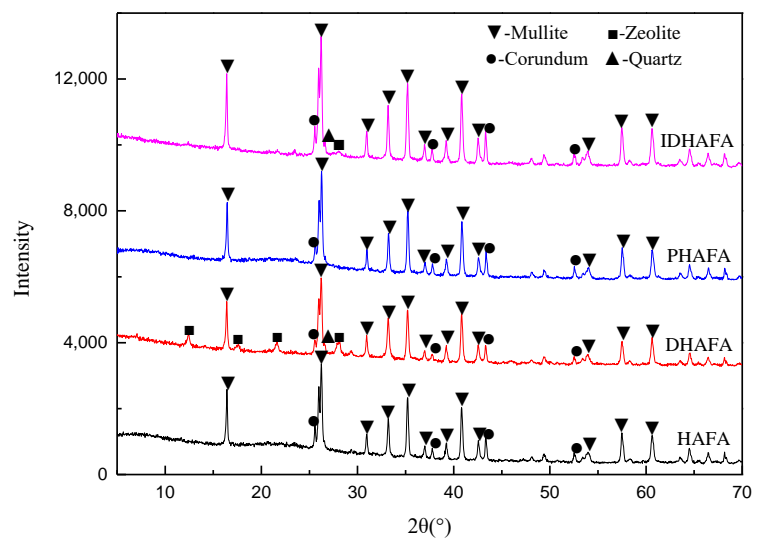

Figure 9. X-ray diffraction (XRD) patterns of HAFA, DHAFA, PHAFA, and IDHAFA.

Figure 10 shows the obtained $\mathrm{N}_{2}$ adsorption isotherms and pore size distribution. It is observed that the specific surface areas are in the order of DHAFA $>$ IDHAFA $>$ PHAFA $>$ HAFA. Very low $\mathrm{N}_{2}$ adsorption is observed in HAFA (surface area $=2.886 \mathrm{~m}^{2} / \mathrm{g}$ ), but a high $\mathrm{N}_{2}$ adsorption is observed for PHAFA for relative pressure (P/P0) between 0.5-1.0 (surface area $=13.737 \mathrm{~m}^{2} / \mathrm{g}$ ), IDHAFA (surface area $=18.519 \mathrm{~m}^{2} / \mathrm{g}$ ), and DHAFA (surface area $=21.460 \mathrm{~m}^{2} / \mathrm{g}$ ). The larger specific surface area of PHAFA than HAFA is ascribed to the removal of iron oxide and calcium oxide after physical and chemical activation. The increased surface area of IDHAFA and DHAFA may be related to the removal of amorphous silica wrapped in the mullite and the formation of a new zeolite phase. It also indicated that there are fewer mesopores in HAFA $(4 \mathrm{~nm})$ and PHAFA $(3 \mathrm{~nm})$; however, except for the smaller mesopores (3-4 $\mathrm{nm}$ ) of DHAFA and IDHAFA, larger mesopores $(13 \mathrm{~nm})$ appeared in DHAFA, and even larger mesopores (10-14 $\mathrm{nm}$ ) appeared in IDHAFA. 

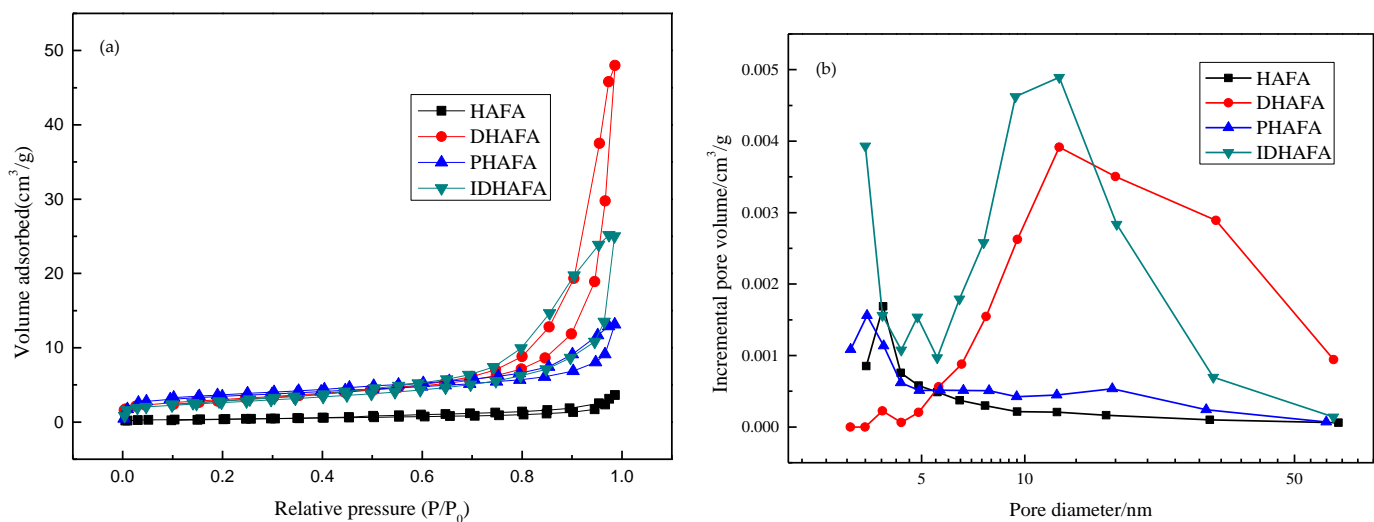

Figure 10. Nitrogen adsorption-desorption isotherms and pore size distribution of HAFA, DHAFA, PHAFA, and IDHAFA. (a) Nitrogen adsorption-desorption isotherms, (b) Pore size distribution.

Figure 11 shows the weight loss curve under conditions of protective gas air atmosphere and heating rate of $10^{\circ} \mathrm{C} / \mathrm{min}$. It is observed that both HAFA and PHAFA have smaller weight loss because there are small amounts of unburned carbon removed. On the other hand, DHAFA and IDHAFA show higher weight losses due to the formation of byproduct zeolite containing crystalline water. When the temperature is higher than $700{ }^{\circ} \mathrm{C}$, no weight loss was observed. It should be noted that the weight loss of IDHAFA is still less than that of DHAFA, which also indicates that the pretreatment suppresses the occurrence of side reactions of fly ash after desilication and reduces the formation of zeolite.

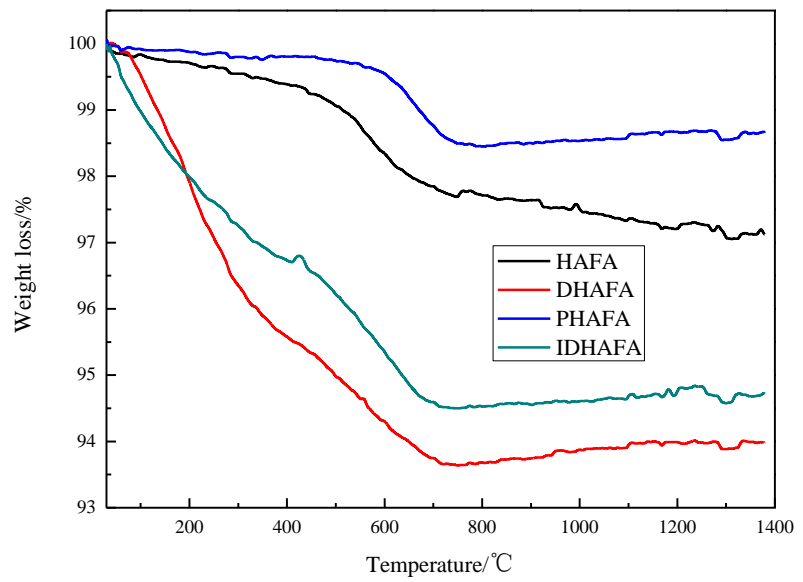

Figure 11. Thermogravimetric (TG) results for HAFA, DHAFA, PHAFA, and IDHAFA.

As demonstrated in Figure 12, the shape of the raw HAFA (Figure 12a) is more complicated. The spherical mullite and the irregular glass are intertwined and inlaid with each other, and the interface is not clear. After the conventional predesilication reaction, it is found that DHAFA (Figure 12c) is mainly composed of spherical mullite crystals, and the irregular glass phase essentially disappears. However, the spherical shape from the EDS analysis indicates that a large amount of the zeolite particles is covered, indicating a small amount of soluble oxidation in the conventional predesilication reaction. The aluminum reacted with sodium silicate solution re-enters DHAFA, resulting in a low desilication rate. After the physical and chemical activation treatment, it is observed that the mullite and the amorphous glass phase of PHAFA (Figure 12b) have been separated. This is highly beneficial for desilication. The surface of IDHAFA (Figure 12e) is smoother than the DHAFA (Figure 12c), and the particles in IDHAFA mainly consist of pure mullite crystals. Furthermore, the EDS analysis showed that the alkalinity of IDHAFA (Na $0.9 \mathrm{wt}$ \% \%) (Figure 12f) is less than DHAFA (Na 2.39 wt. \%) (Figure 12d), indicating that the side reaction of the zeolite $\left(\mathrm{Na}_{6} \mathrm{Al}_{6} \mathrm{Si}_{10} \mathrm{O}_{32} \cdot 12 \mathrm{H}_{2} \mathrm{O}\right)$ was greatly reduced. 

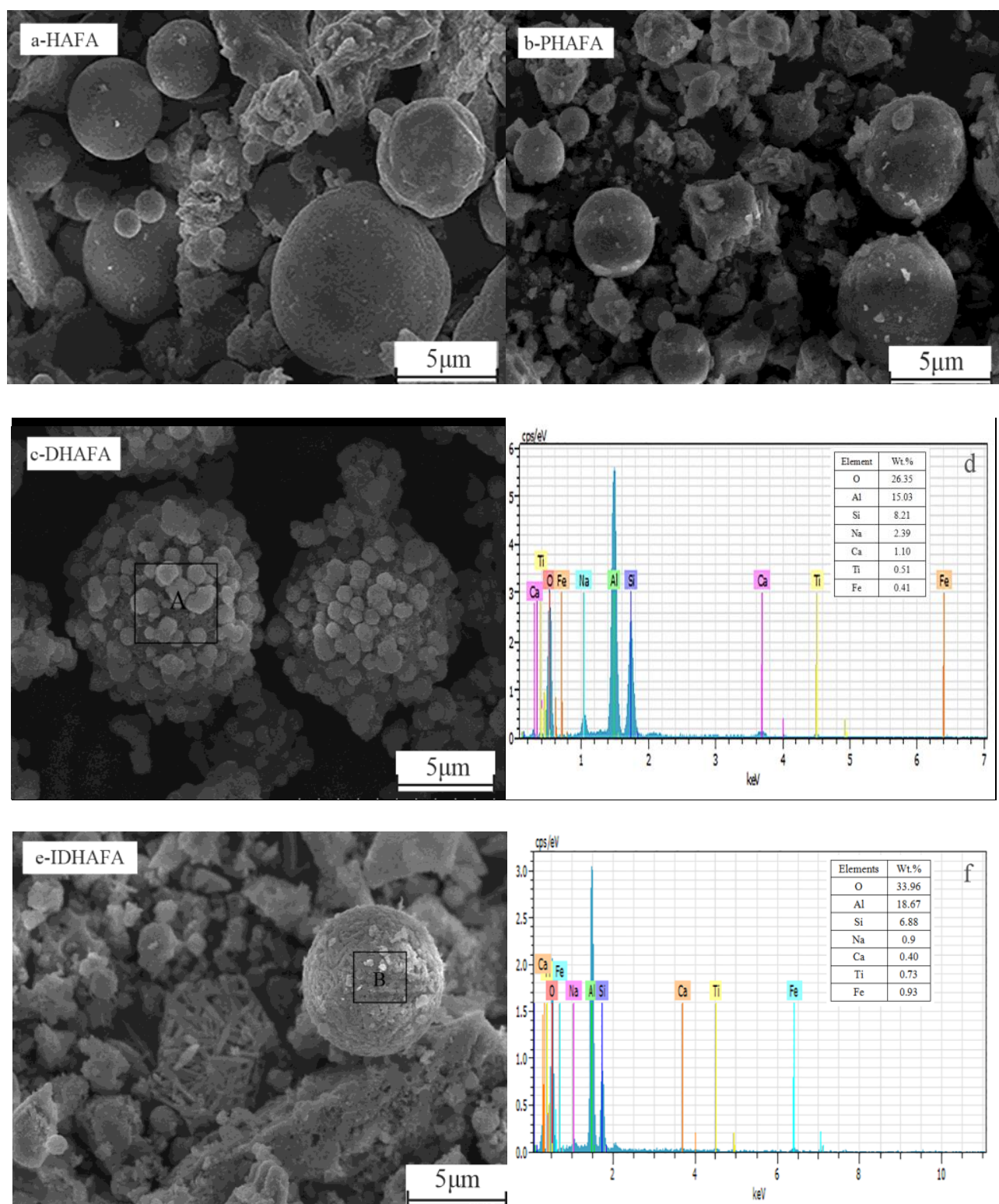

Figure 12. Scanning electron microscopy (SEM) and energy-dispersive X-ray spectroscopy (EDS) results: (a) HAFA, (b) PHAFA, (c,d) DHAFA, (e,f) IDHAFA.

As a conclusion, the mechanism of enhanced desilication can be summarized as follows.

First, the spherical mullite and the amorphous glass phase are separated by physical activation, and the reactivity of the $\mathrm{SiO}_{2}$ and $\mathrm{Al}_{2} \mathrm{O}_{3}$ in the glass phase is improved.

Second, the $\mathrm{Al}_{2} \mathrm{O}_{3}$ in the glass phase is dissolved and removed by hydrochloric acid.

$$
\mathrm{Al}_{2} \mathrm{O}_{3} \text { (amorphous) }+\mathrm{HCl}=\mathrm{AlCl}_{3}+\mathrm{H}_{2} \mathrm{O}
$$

Third, the $\mathrm{SiO}_{2}$ in the glass phase is dissolved by sodium hydroxide with almost no side reactions to form zeolite $\left(\mathrm{Na}_{6} \mathrm{Al}_{6} \mathrm{Si}_{10} \mathrm{O}_{32} \cdot 12 \mathrm{H}_{2} \mathrm{O}\right)$. Therefore, only the mullite, corundum, and quartz are left in the fly ash after enhanced desilication.

$$
2 \mathrm{NaOH}+\mathrm{SiO}_{2} \text { (amorphous) }=\mathrm{Na}_{2} \mathrm{SiO}_{3}+\mathrm{H}_{2} \mathrm{O}
$$




\section{Conclusions}

Improvement in desilication efficiency is important not only for obtaining more silicon resources, but also for more economical and efficient extraction of alumina.

A new process that combined physical and chemical activation and predesilication has been proposed. By using physical and chemical activation, the desilication efficiency of HAFA increased from $38.4 \%$ to $53.2 \%$. The reaction temperature has a significant effect on the desilication efficiency.

Kinetic study results show that the enhanced desilication process after physical and chemical activation fits with an unreacted shrinking core model of the liquid-solid reaction. The desilication reaction is divided into two stages. The earlier stage is controlled by chemical reaction and the activation energy is $52.05 \mathrm{~kJ} / \mathrm{mol}$ and the later stage is also controlled by chemical reaction and the activation energy is $58.45 \mathrm{~kJ} / \mathrm{mol}$.

This result indicates that physical and chemical activation suppresses the formation of zeolite, thereby improving the desilication efficiency and further improving the $A / S$ of the fly ash; results which are very advantageous for the next step of alumina extraction.

Author Contributions: Methodology, J.S.; experiments, data analyze and writing—original draft preparation, Y.G.; writing — review and editing S.-Y.S. and T.-A.Z.; formal analysis, G.L.

Acknowledgments: This research was funded by National Key R\& D Program of China grant number 2017YFB0603103.

Conflicts of Interest: The authors declare no conflict of interest.

\section{References}

1. Sun, J.; Chen, P. Resourcing utilization of high alumina fly ash. Adv. Mater. 2013, 652-654, 2570-2575. [CrossRef]

2. Blissett, R.S.; Rowson, N.A. A review of the multi-component utilisation of coal fly ash. Fuel 2012, 97, 1-23. [CrossRef]

3. Jing, L.; Dong, Y.; Dong, X.; Hampshire, S.; Li, Z.; Zhu, Z.; Li, L. Feasible recycling of industrial waste coal fly ash for preparation of anorthite-cordierite based porous ceramic membrane supports with addition of dolomite. J. Eur. Ceram. Soc. 2016, 36, 1059-1071.

4. $\quad \mathrm{Li}, \mathrm{S} . ; \mathrm{Wu}, \mathrm{W} . ; \mathrm{Li}, \mathrm{H} . ; \mathrm{Hou}, \mathrm{X}$. The direct adsorption of low concentration gallium from fly ash. Sep. Technol. 2016, 51, 395-402. [CrossRef]

5. Hu, P.; Hou, X.; Zhang, J.; Li, S.; Hao, W.; Damø, A.J.; Li, H.; Wu, Q.; Xi, X. Distribution and occurrence of lithium in high-alumina-coal fly ash. Int. J. Coal. Geol. 2018, 189, 27-34. [CrossRef]

6. Dai, S.; Lei, Z.; Peng, S.; Chou, C.L.; Wang, X.; Yong, Z.; Dan, L.; Sun, Y. Abundances and distribution of minerals and elements in high-alumina coal fly ash from the jungar power plant, Inner Mongolia, China. Int. J. Coal. Geol. 2010, 81, 320-332. [CrossRef]

7. Lanzerstorfer, C. Fly ash from coal combustion: Dependence of the concentration of various elements on the particle size. Fuel 2018, 228, 263-271. [CrossRef]

8. Bai, G.; Teng, W.; Wang, X.; Qin, J.; Xu, P. Alkali desilicated coal fly ash as substitute of bauxite in lime-soda sintering process for aluminum production. Trans. Nonferr. Met. Soc. 2010, 20, s169-s175. [CrossRef]

9. Xiao, H.W.; Bao, D.W.; Yong, F.X.; Xiao, T.L.; Qi, S. The optimization of sintering process for alumina extraction from fly ash. Adv. Mater. 2014, 878, 264-270.

10. Cheng-You, W.U.; Hong-Fa, Y.U.; Zhang, H.F. Extraction of aluminum by pressure acid-leaching method from coal fly ash. Trans. Nonferr. Met. Soc. 2012, 22, 2282-2288.

11. Shemi, A.; Ndlovu, S.; Sibanda, V.; Dyk, L.D.V. Extraction of alumina from coal fly ash using an acid leach-sinter-acid leach technique. Hydrometallurgy 2015, 157, 348-355. [CrossRef]

12. Wang, R.C.; Zhai, Y.C.; Xiao-Wei, W.U.; Ning, Z.Q.; Pei-Hua, M.A. Extraction of alumina from fly ash by ammonium hydrogen sulfate roasting technology. Trans. Nonferr. Met. Soc. 2014, 24, 1596-1603. [CrossRef]

13. Sun, Z.; Li, H.; Bao, W.; Wang, C.; Sun, Z.; Li, H.; Bao, W.; Wang, C. Mineral phase transition of desilicated high alumina fly ash with alumina extraction in mixed alkali solution. Int. J. Miner. Process. 2016, 153, 109-117. [CrossRef] 
14. Gong, B.; Chong, T.; Zhuo, X.; Zhao, Y.; Zhang, J. Mineral changes and trace element releases during extraction of alumina from high aluminum fly ash in Inner Mongolia, China. Int. J. Coal. Geol. 2016, 166, 96-107. [CrossRef]

15. Yuan, H.; Huang, F.; Wang, L.; Li, H. Study of sinter technique with low alumina-silica ratio. Guizhou Chem. Ind. 2004, 29, 21-27. (In Chinese)

16. Meher, S.N.; Rout, A.K.; Padhi, B.K. Extraction of alumina from red mud by divalent alkaline earth metal soda ash sinter process. In Light Metals; Springer: Cham, Switzerland, 2011; pp. 231-236.

17. Lin, I.J.; Malts, N.; Shindler, Y. The complex chemical treatment of alumina-silica-containing materials. J. Mater. Synth. Process. 1998, 6, 27-35. [CrossRef]

18. Inada, M.; Eguchi, Y.; Enomoto, N.; Hojo, J. Synthesis of zeolite from coal fly ashes with different silica-alumina composition. Fuel 2005, 84, 299-304. [CrossRef]

19. Mouhtaris, T.; Charistos, D.; Kantiranis, N.; Filippidis, A.; Kassoli-Fournaraki, A.; Tsirambidis, A. GIS-type zeolite synthesis from Greek lignite sulphocalcic fly ashes promoted by $\mathrm{NaOH}$ solutions. Microporous Mesoporous Mater. 2003, 61, 57-67. [CrossRef]

20. Lin, C.F.; Hsi, H.C. Resource recovery of waste fly ash: Synthesis of zeolite-like materials. Environ. Sci. Technol. 1995, 29, 1109-1117. [CrossRef] [PubMed]

21. Murayama, N.; Yamamoto, H.; Shibata, J. Mechanism of zeolite synthesis from coal fly ash by alkali hydrothermal reaction. Int. J. Miner. Process. 2002, 64, 1-17. [CrossRef]

22. Zhang, J.B.; Li, S.P.; Li, H.Q.; He, M.M. Acid activation for pre-desilicated high-alumina fly ash. Fuel Process. Technol. 2016, 151, 64-71. [CrossRef]

23. Zhu, G.; Wei, T.; Sun, J.; Gong, Y.; Liu, L. Effects and mechanism research of the desilication pretreatment for high-aluminum fly ash. Energy Fuels 2013, 27, 6948-6954. [CrossRef]

24. Zhang, J.; Li, S.; Li, H.; Wu, Q.; Xi, X.; Li, Z. Preparation of al-si composite from high-alumina coal fly ash by mechanical-chemical synergistic activation. Ceran. Int. 2017, 43, 6532-6541. [CrossRef]

25. Zhang, J.; Li, H.; Li, S.; Hu, P.; Wu, W.; Wu, Q. Mechanism of mechanical-chemical synergistic activation for preparation of mullite ceramics from high-alumina coal fly ash. Ceran. Int. 2018, 44, 3884-3892. [CrossRef]

26. He, S.; Li, H.; Li, S.; Li, Y.; Xie, Q. Kinetics of desilication process of fly ash with high aluminum from pulverized coal fired boiler in alkali solution. Chin. J. Nonferr. Met. 2014, 24, 1888-1894. (In Chinese) 